\title{
Une place à part dans l'univers muséal français
}

Une collection bien outillée pour des missions diversifiées

A special place in the French Museum world. A well-equipped collection for

diversified missions

\section{Dominique Antérion}

\section{Q OpenEdition}

1 Journals

\section{Édition électronique}

URL : http://journals.openedition.org/artefact/2426

DOI : 10.4000/artefact.2426

ISSN : 2606-9245

Éditeur :

Association Artefact. Techniques histoire et sciences humaines, Presses universitaires du Midi

\section{Édition imprimée}

Date de publication : 6 décembre 2018

Pagination : 328-333

ISBN : 978-2-8107-0595-5

ISSN : 2273-0753

\section{Référence électronique}

Dominique Antérion, « Une place à part dans l'univers muséal français », Artefact [En ligne], 8| 2018, mis en ligne le 21 juin 2019, consulté le 28 novembre 2020. URL : http://journals.openedition.org/ artefact/2426; DOI : https://doi.org/10.4000/artefact.2426

\section{(ब) $\odot \Theta$}

Artefact, Techniques, histoire et sciences humaines est mise à disposition selon les termes de la Licence Creative Commons Attribution - Pas d'Utilisation Commerciale - Pas de Modification 4.0 International. 


\title{
Une place à part dans l'univers muséal français
}

\author{
Une collection bien outillée pour des missions \\ diversifiées
}

Dominique Antérion

\section{Résumé}

Le musée du 11 Conti-Monnaie de Paris, s'inscrit dans une tradition muséale vieille de plus de deux siècles : Cabinet de minéralogie à la fin du xvıII siècle, musée monétaire avec le règne de Louis Philippe... Chaque fois le musée revêt une dimension professionnelle à l'adresse des artisans ou techniciens de la Monnaie de Paris. De nos jours, et au-delà du musée du 11 Conti ouvert au plus grand nombre, la collection continue de jouer ce rôle de «fonction support ».

\section{Mots-clés}

musée, collection, Monnaie de Paris, Hôtel de la Monnaie, minéralogie, Sage, comte de Sussy

9 Dominique Antérion, «Une place à part dans l'univers muséal français », Artefact, 8, 2018, p. 328-333. 


\section{A special place in the French Museum world}

A well-equipped collection for diversified missions

\section{Abstract}

The 11 Conti-Paris Mint Museum falls within a two-centuries-old museum tradition: first a mineralogy cabinet at the end of the $18^{\text {th }}$ century, then turned into a mint museum under Louis Philippe. The museum always seems to feed the Mint's craftsmen and technicians' inspiration. Nowadays, beyond the 11 Conti Museum and its wide audience, its collection remains a standard.

\section{Keywords}

museum collection, Monnaie de Paris, Hôtel de la Monnaie, mineralogy, Sage, comte de Sussy 
$\neg$ andis que le musée du 11 Conti - Monnaie de Paris ${ }^{1}$ s'inscrit peu à $^{\prime}$ peu dans le paysage culturel français, le statut et par là même l'ori1 ginalité des collections de l'établissement demeurent encore affaire d'initiés. Héritière des institutions d'Ancien Régime que furent la Cour des Monnaies, la Monnaie des espèces, et la Monnaie des Médailles, la Monnaie de Paris - par l'origine même de ses collections et leur vocation diffère des autres institutions "numismatiques " (cabinet des Médailles de la Bibliothèque nationale de France ou collections de la Banque de France, pour ne citer qu'elles). Adossée à une « entreprise » d'État, la collection historique de la Monnaie de Paris a valeur de référent bien plus que d'agrément. La donne se trouve clairement exposée aux origines même du premier musée.

\section{Aux origines était un cabinet de minéralogie}

Dès les années 1780, l'Hôtel de la Monnaie se trouve pourvu d'un cabinet de minéralogie constitué par l'académicien des sciences Balthazar Georges Sage (1740-1824). La collection, était destinée à être observée et étudiée par des auditeurs de la Chaire de minéralogie docimastique ${ }^{2}$, instituée officiellement par arrêt du Conseil du roi le 11 juin 1778 (Fig. 1). Inventoriée, la collection fut publiée en 1784 avec supplément en 1787. Ce "musée " qui n'en portait pas officiellement le nom était clairement destiné à un usage pratique basé sur la comparaison et la modélisation. Officialisée en 1783 sous le nom d'École royale des mines, la chaire quitta les lieux et avec elle la collection de minéraux, minerais et modèles qui se trouva partagée entre l'École des mines et le Muséum national d'histoire naturelle. La vocation «muséale» du Quai Conti était toutefois tracée.

\footnotetext{
1. Troisième à s'installer sur le site historique de l'Hôtel de la Monnaie (Paris $1^{\text {er }}$ ) et ouvert au public depuis le 30 septembre 2017.

2. Branche de la minéralogie visant à optimiser, à partir d'un minerai, la séparation entre le métal recherché (or et argent notamment) et les autres éléments qui lui sont naturellement associés.
} 


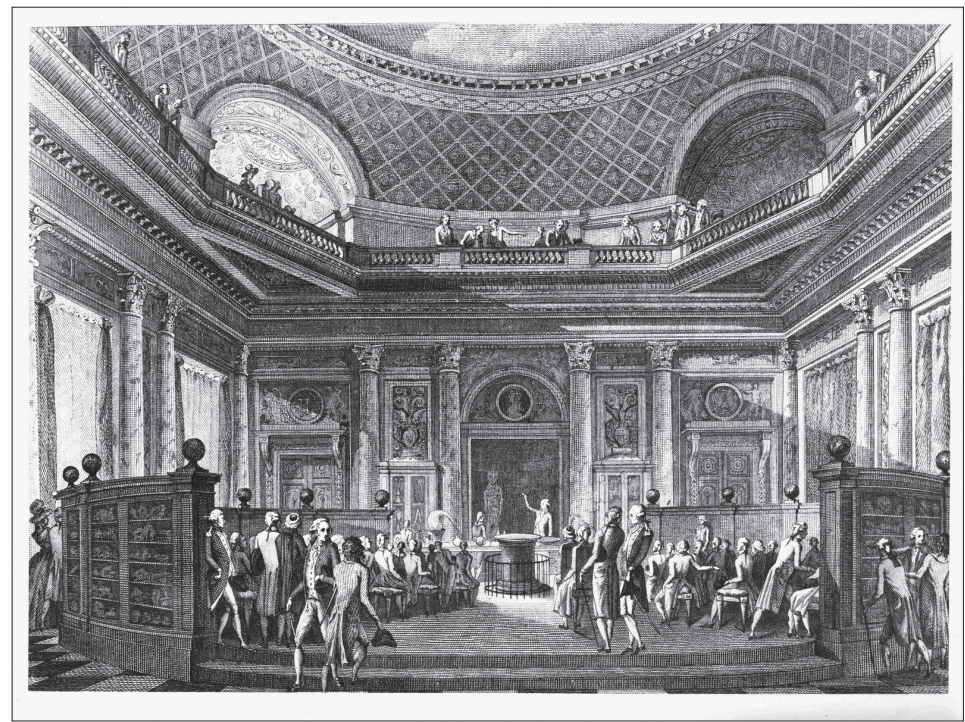

Fig. 1. - François-Denis Née, La Chaire de minéralogie de B.G. Sage dans le salon d'honneur

Gravure, vers 1780.

Archives de la Monnaie de Paris @

\section{Du cabinet de Sage au musée de Louis- Philippe}

Il revint à Jean-Baptiste Henry Collin (1776-1837), comte de Sussy, président de la Commission des Monnaies de lancer en 1827 un nouveau projet de musée, davantage axé sur les fabrications monétaires. Une fois encore, la démarche se veut référente dans le domaine. Le 12 septembre 1827, de Sussy écrit à Joseph de Villèle (1773-1854), alors ministre des finances (déjà tutelle des lieux) :

Votre Excellence n'apprendra pas sans satisfaction l'établissement dans l'Hôtel des monnaies, sans aucun frais pour son Ministère, d'une espèce de musée, semblable à ceux qui existent dans les autres Monnaies d'Europe, et que je me propose de compléter par la réunion $1^{\circ}$ De tous les modèles et poinçons, coins, appareils et machines servant à la fabrication des monnaies de l'État ; $2^{\circ}$ Des différents produits monétaires; $3^{\circ}$ De la collection générale des 
monnaies de France et de toutes les monnaies étrangères ${ }^{3} ; 4^{\circ} \mathrm{Et}$ des instruments employés à la marque et à l'insculpation des poinçons pour la garantie des ouvrages d'or et d'argent [...]. M. Darcet, membre de l'Institut et inspecteur général des essais se charge de suivre près du ministère de l'Intérieur l'obtention de la collection déjà promise, des minerai et substances métalliques employées dans les travaux monétaires ${ }^{4}$.

Le musée n'était pas encore achevé, que survint l'ordonnance royale du 24 mars 1832 qui réunit à l'Administration des Monnaies, la Monnaie des Médailles dépendant jusqu’à cette date de la Maison du roi. Conséquence immédiate : les fonds de coins et poinçons des médailles et jetons, anciens et modernes, furent joints à celui du musée monétaire ${ }^{5}$, faisant de la collection de l'Hôtel de la Monnaie un ensemble sans équivalent ! Lié par des métiers communs et des techniques similaires l'univers des monnaies se trouvait lié de manière définitive à l'art des médailles ${ }^{6}$. Le Grand Salon (actuelle salle Guillaume Dupré) ainsi que les salons attenants et les galeries supérieures furent affectés à l'exposition de ces collections (Fig. XXI, cahier couleur). Le nouveau musée fut inauguré le 8 novembre 1833 par Louis-Philippe accompagné de la reine Marie-Amélie et du roi des Belges Léopold $1^{\text {er }}$ (Fig. XX, cahier couleur). Il sera en 1903 complété par un mobilier d'exposition de style Louis XVI qui demeure aujourd'hui pour partie conservé. Dès lors le musée était amené à devoir se développer par le dépôt que l'on y faisait des exemplaires des monnaies et médailles frappés chaque année par l'établissement ${ }^{7}$. S’y trouvaient également versés les outillages de frappe et autres poinçons.

\footnotetext{
3. Monnaies principalement issues du médaillier de la Cour des Monnaies.

4. L'actuelle salle des matières premières par laquelle s'ouvre le musée du 11 Conti - Monnaie de Paris, renoue totalement avec cette idée, elle-même héritée du cabinet de Sage. Archives de la Monnaie de Paris, série M1.

5. Article 6 de l'ordonnance du 24 mars 1832. Un inventaire en avait été réalisé par Nicolas de Launay en 1697.

6. Ce dont la Monnaie de Paris témoigne pleinement aujourd'hui.

7. À noter toutefois le décret du 16 février 1861 qui autorisa le Cabinet des Médailles de la Bibliothèque Impériale à choisir dans les collections de la Monnaie toute pièce manquante à sa collection. La collection s'en releva tant bien que mal grâce à la dynamique de ses archivistes et conservateur successifs parmi lesquels on citera Fernand Mazerolle, Jean Belaubre ou encore Jean-Luc Desnier.
} 


\section{Les fabrications d'hier au service des fabrications d'aujourd'hui et de demain}

Accessible aux invités de marque ou sur autorisation spéciale, la collection est surtout destinée aux graveurs et autres directeurs des fabrications pour lesquels ces fonds constituaient - au-delà de la mémoire artistique et technique de ce qui était devenu entre-temps l'Administration des Monnaies et Médailles ${ }^{8}$ - une référence indispensable à toute fabrication ultérieure. Une galerie de "styles »!

Dans le domaine de la médaille le Catalogue Général de la Monnaie de Paris témoigne de la source inépuisable d'inspiration que représente la collection. Qu'il s'agisse de refrappes, de mariages de coins ou de réutilisation partielle d'un motif, les productions n'ont pas manqué, tout au long des $\mathrm{XIX}^{\mathrm{e}}$ et $\mathrm{XX}^{\mathrm{e}}$ siècles de faire référence aux œuvres conservées. Sur le plan monétaire, et à partir de la période révolutionnaire, la conservation des coins et poinçons se systématise. La cohérence de l'ensemble, pour les $\mathrm{XIX}^{\mathrm{e}}$ et $\mathrm{XX}^{\mathrm{e}}$ siècles tranche avec la période précédente qui demeure - à la différence des outillages de médailles - totalement lacunaire pour la période d'Ancien Régime. Là encore, les graveurs de la Monnaie par l'accès à cet ensemble, s'y réferent autant pour s'en inspirer que pour aussi mieux s'en détacher.

Aujourd'hui visible du plus grand nombre, le musée du 11 Conti poursuit cette double mission d'éduquer les publics et de documenter les professionnels de l'entreprise " Monnaie de Paris » : graveurs, estampeurs, commerciaux. Une " fonction support » culturelle et une marque de fabrique certaine.

8. Devenue régie sous ce nom en 1879, l'Administration (puis la Direction) des monnaies et médailles, rattachée au ministère des Finances changea de statut en 2007 pour devenir Établissement public industriel et commercial sous le nom déjà bien connu de Monnaie de Paris. Concernant les alinéas des statuts de l'ÉPIC relatifs au devenir des collections. 